\title{
Relationship of flow-volume curve pattern on pulmonary function test with clinical and radiological features in idiopathic pulmonary fibrosis
}

Hiroaki Nakagawa ${ }^{1,2^{*}}$ (D), Ryota Otoshi ${ }^{2}$, Kohsuke Isomoto $^{3}$, Takuma Katano ${ }^{2}$, Tomohisa Baba ${ }^{2}$, Shigeru Komatsu ${ }^{2}$, Eri Hagiwara ${ }^{2}$, Yasutaka Nakano ${ }^{1}$, Ichiro Kuwahira ${ }^{4}$ and Takashi Ogura ${ }^{2}$

\begin{abstract}
Background: The flow-volume (FV) curve pattern in the pulmonary function test (PFT) for obstructive lung diseases is widely recognized. However, there are few reports on FV curve pattern in idiopathic pulmonary fibrosis (IPF). In this study, we investigated the relationship between FV curve pattern and clinical or radiological features in IPF.

Methods: The FV curves on PFTs and chest high-resolution computed tomography (HRCT) images of 130 patients with IPF were retrospectively evaluated. The FV curves were divided into four groups based on the presence or absence of the convex and concave patterns: convex/concave, non-convex/concave, convex/non-concave, and non-convex/non-concave. Using a computer-aided system, CT honeycombing area (\%HA) and subtracted low attenuation area (\%sLAA) were quantitatively measured. To assess the distribution of $C T$ findings, the lung area was divided into upper, lower, central, and peripheral areas. The relationships of FV curve patterns with patient characteristics, spirometry results, and quantitative $\mathrm{CT}$ findings were evaluated.

Results: The patients with convex pattern was identified in 93 (71.5\%) and concave pattern in 72 (55.4\%). Among the four groups, patients with the convex/non-concave pattern had significantly lower forced vital capacity (FVC) and higher \%HA of the upper/peripheral lung area ( $p=0.018$, and $p=0.005$, respectively). The convex/non-concave pattern was a significant predictor of mortality for IPF (hazard ratio, 2.19; $p=0.032$ ).
\end{abstract}

Conclusions: Patients with convex/non-concave pattern in FV curve have lower FVC and poorer prognosis with distinct distribution of fibrosis. Hence, FV curve pattern might be a useful predictor of mortality in IPF.

Keywords: Concave, Convex, Flow-volume curve, Honeycombing area, Idiopathic pulmonary fibrosis

\footnotetext{
* Correspondence: hiroaki@belle.shiga-med.ac.jp

${ }^{1}$ Division of Respiratory Medicine, Department of Internal Medicine, Shiga

University of Medical Science, Seta Tsukinowa-cho, Otsu, Shiga 520-2192,

Japan

${ }^{2}$ Department of Respiratory Medicine, Kanagawa Cardiovascular and

Respiratory Center, Kanagawa, Japan

Full list of author information is available at the end of the article
}

(c) The Author(s). 2020 Open Access This article is licensed under a Creative Commons Attribution 4.0 International License, which permits use, sharing, adaptation, distribution and reproduction in any medium or format, as long as you give appropriate credit to the original author(s) and the source, provide a link to the Creative Commons licence, and indicate if changes were made. The images or other third party material in this article are included in the article's Creative Commons licence, unless indicated otherwise in a credit line to the material. If material is not included in the article's Creative Commons licence and your intended use is not permitted by statutory regulation or exceeds the permitted use, you will need to obtain permission directly from the copyright holder. To view a copy of this licence, visit http://creativecommons.org/licenses/by/4.0/ The Creative Commons Public Domain Dedication waiver (http://creativecommons.org/publicdomain/zero/1.0/) applies to the data made available in this article, unless otherwise stated in a credit line to the data. 


\section{Background}

Idiopathic pulmonary fibrosis (IPF) is a specific form of chronic and progressive fibrosing interstitial pneumonia of unknown cause [1-3]. Baseline pulmonary function test (PFT) values are reportedly associated with survival in IPF, with forced vital capacity (FVC) and diffusing capacity for carbon monoxide $\left(\mathrm{DL}_{\mathrm{CO}}\right)$ used as predictors of survival [4-8]. In particular, FVC is widely used to assess the severity and predict mortality in $\operatorname{IPF}[4,5]$. However, in patients having both IPF and expansive emphysema, FVC may not be an appropriate indicator of the severity of IPF [9].

In another aspect of the PFT, the flow-volume (FV) curve demonstrates a portion of the respiratory dynamics. If the FV curve exhibits a concave pattern, it indicates that the patient's airway is obstructed during exhalation and an obstructive ventilatory disorder is present. The concave pattern is typical in cases of severe asthma and severe chronic obstructive pulmonary disease (COPD) [10, 11]. Conversely, a convex pattern of the FV curve has been reported in interstitial lung disease (ILD) [12]. A previous study reported the presence of increased elastic recoil forces and decreased dynamic airway compression in the large bronchi in ILD [12]. These patterns have been classified by visual inspection without clear definition. However, in patients having both expansive fibrosis and emphysema, we cannot visualize the pattern of the FV curve.

To the best of our knowledge, so far, there has been only one report on FV curves in IPF [12]. In the present study, we aimed to clarify the relationship between FV curve pattern and clinical or radiological features in IPF.

\section{Methods}

\section{Study design and patients}

All patients with IPF-diagnosed in accordance with the 2011 IPF guidelines [13] - who visited the outpatient clinic of our hospital between April 2012 and March 2015 were enrolled in this study. Patients with secondary interstitial pneumonitis (such as collagen vascular disease, pneumonia caused by occupational or environmental exposure, chronic hypersensitivity pneumonitis, and drug-induced pneumonia), combined pulmonary fibrosis and emphysema (CPFE), and pleuroparenchymal fibroelastosis (PPFE) were excluded. Patients who had not undergone a PFT and high-resolution computed tomography (HRCT) within three months from the first visit were excluded. Patients whose PFT was presence of cough in the FV curve were also excluded. Mortality and survival data up to December 31, 2017, were collected. The study protocol conformed to the Declaration of Helsinki and was approved by the ethics committee of Kanagawa Cardiovascular and Respiratory Center (approval number KCRC-17-0027). The need for informed consent was waived because of the retrospective study design.

To evaluate what FV curve meant in IPF, the classification of FV curve was performed using the following steps: 1; dividing convex or non-convex with visual inspection, 2; dividing concave or non-concave with the ratio of the maximal expiratory flows at 50 and $25 \%$ of the FVC $\left(\mathrm{MEF}_{50} / \mathrm{MEF}_{25}\right), 3$; mixing these two shapes of flow to create four groups. First, the patients' FV curves were independently reviewed by two thoracic physicians (R.O. and K.I.) who were blinded to the clinical and radiological data and all other PFT data, except the FV curve. The two physicians visually evaluated the FV curves and classified the pattern as convex or nonconvex, as previously described [14, 15] (Fig. 1). In cases of conflict between the two reviewers, a third thoracic physician (T.K.) made the decision. Second, toevaluate the presence of peripheral airway obstruction, $\mathrm{MEF}_{50} /$ $\mathrm{MEF}_{25}$ was calculated. The FV curve patterns were again divided into two categories based on the $\mathrm{MEF}_{50} / \mathrm{MEF}_{25}$ ratio, with $\mathrm{MEF}_{50} / \mathrm{MEF}_{25} \geq 4$ defined as the concave pattern and $\mathrm{MEF}_{50} / \mathrm{MEF}_{25}<4$ defined as the non-concave pattern (Fig. 1). Third, we divided into four groups based on the presence or absence of the convex pattern and the concave pattern. The patient groups with the convex/concave pattern, non-convex/concave pattern, convex/non-concave pattern, and non-convex/non-concave pattern were defined as A group, B group, C group, and D group, respectively (Fig. 1). Composite physiologic index (CPI) and gender, age, and physiology stage (GAP stage) were determined as previously described $[16,17]$. The PFTs had been performed in accordance with the Japanese Respiratory Society guidelines [18].

Chest HRCT images were acquired using the Toshiba Aquillion ONE (Toshiba Medical Systems Corp., Otawara, Tochigi, Japan). These images were reconstructed with $0.5-1.0 \mathrm{~mm}$ slice thickness and $10-\mathrm{mm}$ intervals. A computer-aided method for quantitative CT analysis of honeycombing area was used to automatically measure honeycombing areas on whole HRCT images, as previously described [19]. In brief, low-attenuation areas enclosed by thick walls were extracted as honeycombing areas, and the sum of honeycombing areas in all slices was calculated as the HA. This HA included traction bronchiectasis. Next, the low attenuation area (LAA) was measured, as previously described [20, 21]. This LAA included not only the emphysematous area, but also the honeycombing area and traction bronchiectasis in IPF. We calculated the pure emphysematous area as the subtracted LAA (sLAA), which was obtained by subtracting the HA from the LAA (Fig. 2). The HA and sLAA as a percentage of the lung area were also calculated (\%HA and \%sLAA, respectively). To evaluate the distribution of these CT findings, we divided the lung 


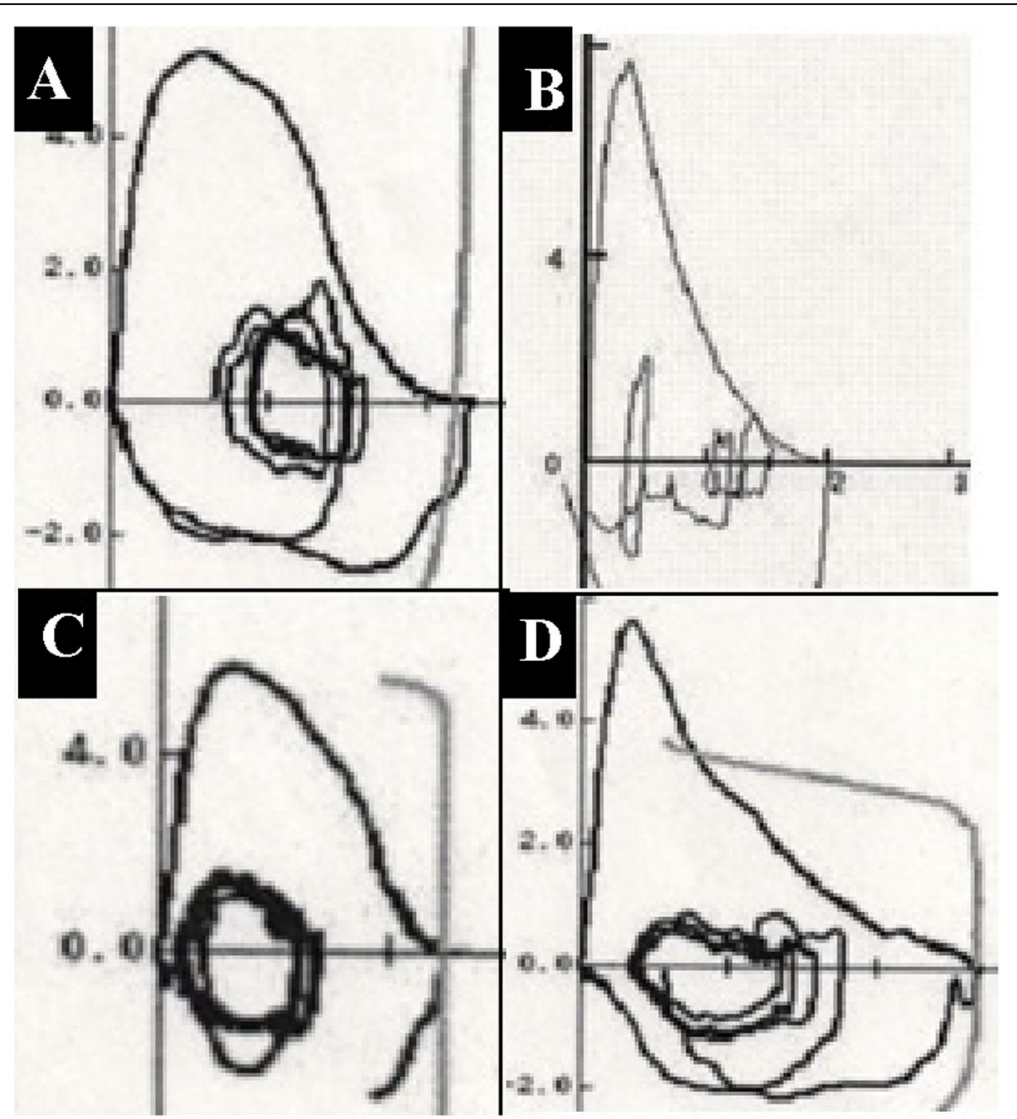

Fig. 1 Flow-volume curves of four patients with idiopathic pulmonary fibrosis. a A 68-year-old woman with the convex/concave pattern (A-group; \%FVC; 86.1\%, \%FEV 1 : 89.3\%, and $\mathrm{MEF}_{50} / \mathrm{MEF}_{25}$-ratio: 5.27). b A 79-year-old man with the non-convex/concave pattern (B-group; \%FVC: 74.1\%, \%FEV: 76.6\%, and $\mathrm{MEF}_{50} / \mathrm{MEF}_{25}$-ratio: 4.31). c An 84-year-old man with the convex/non-concave pattern (C-group; \%FVC: 89.0\%, \% $\mathrm{FEV}_{1}: 109.2 \%$, and $\mathrm{MEF}_{50}$ $\mathrm{MEF}_{25}$-ratio: 1.99). d A 75-year-old man with the non-convex/non-concave pattern (D-group; \%FVC: 82.4\%, \%FEV 1 : 77.4\%, and MEF $\mathrm{MOMEF}_{25}$-ratio: 3.11 )

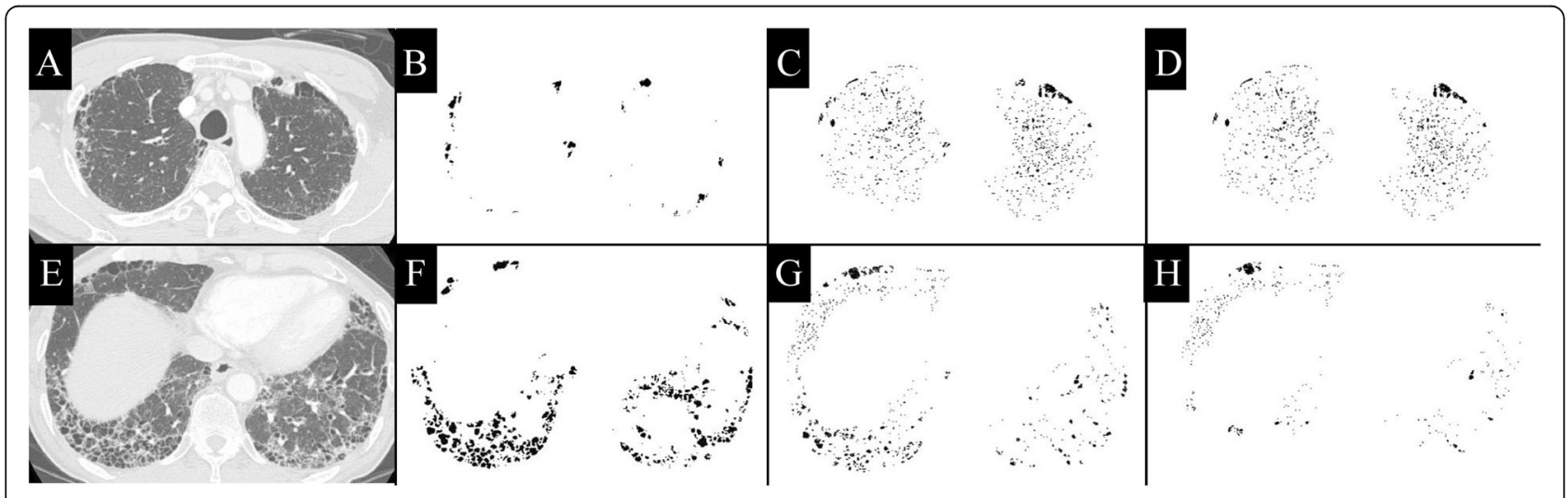

Fig. 2 Quantitative computed tomography (CT) analysis in a 65-year-old man with idiopathic pulmonary fibrosis. a and e Original $C T$ image acquired at the level of the upper and the lower lungs using the lung window setting. $\mathbf{b}$ and $\mathbf{f}$ Honeycombing area (HA) detected as a low attenuation area surrounded by a thick wall. $\mathbf{c}$ and $\mathbf{g}$ Low attenuation area (LAA) detected as under - $960 \mathrm{HU}$. $\mathbf{d}$ and $\mathbf{h}$ Subtracted low attenuation area (SLAA) calculated by subtracting the HA from the LAA 


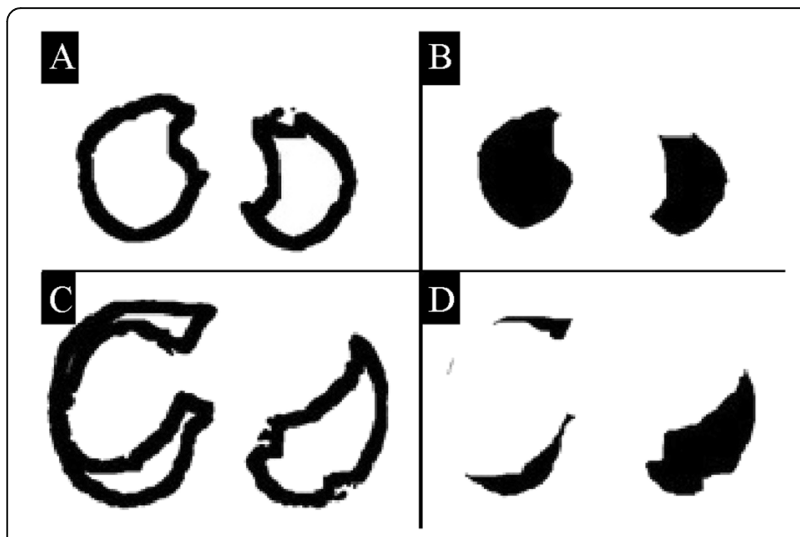

Fig. 3 Quantitative computed tomography $(C T)$ analysis for peripheral and central lung area in the same patient presented in Fig. 2. a and c Peripheral lung area calculated as a 15-pixels area on the pleural side. b and $\mathbf{d}$ Central lung area calculated by removing the peripheral lung area from the whole lung area

area into four areas. First, the location of the tracheal bifurcation was used to divide the lung into the upper and lower areas. Second, the 15-pixel area on the pleural side was defined as the peripheral lung area, and the other areas constituted the central lung area (Fig. 3). A public domain computer program, Image (Version 1.46. National Institutes of Health, Bethesda, MD, USA) was used for the quantitative CT analysis.

\section{Statistical analysis}

The interobserver agreement regarding the classification of the FV curve pattern was evaluated using the kappa statistic. The clinical and radiological variables were compared using the Mann-Whitney $U$ test, Kruskal Wallis test, and the chi-square test. Predictors of time to death were determined using the Cox proportional hazards analysis. Survival analysis was also performed in accordance with the method of Kaplan-Meier, with the endpoint being death. Differences in mortality were assessed using the log-rank test. All statistical analyses were performed using JMP version 9.0.2 (SAS Institute, Cary, NC). For all tests, $p$ values $<0.05$ were considered statistically significant.

\section{Results}

\section{Patient characteristics}

Of the 191 consecutive patients with IPF who visited the outpatient clinic of our hospital between April 2012 and March 2015, 30 patients were excluded because of the absence of HRCT images or PFT results obtained within three months from the first visit. Another 31 patients were excluded because of the presence of cough in the FV curve. Thus, 130 patients with IPF were finally enrolled in this study. The demographic, clinical, and physiologic characteristics of these 130 patients are summarized in Table 1. The median age of the study group was $71(65-76)$ years. Most of the patients (104 patients; $80.0 \%)$ were men and were either current smokers or had a history of smoking (102 patients; 78.5\%). The median \%predicted FVC, forced expiratory volume in $1 \mathrm{~s}\left(\mathrm{FEV}_{1}\right)$, and $\mathrm{DL}_{\mathrm{CO}}$ were $76.2,76.3$, and $70.1 \%$, respectively. The median CPI was 31.3 (18.245.4). Seventy-one (57.3\%) patients were classified as GAP stage I, $50(40.3 \%)$ as stage II, and $3(2.4 \%)$ as stage III. The median follow-up period was 3.0 (1.4-3.8) years.

\section{Flow-volume curve pattern analysis}

Of the 130 patients, 93 (71.5\%) patients had a convex pattern of the FV curve. The agreement between the two physicians was excellent for the convex pattern (kappa = 0.86). There were significant differences between patients with convex and non-convex patterns in gender, body mass index (BMI), and smoking history (in pack-years), but not in FVC, $\mathrm{DL}_{\mathrm{CO}}$, or CPI (Table 2).

The concave pattern was observed in 72 (55.4\%) patients. Significant differences were noted between the concave and non-concave patterns in age, BMI, FVC, and $\mathrm{CPI}$, but not in $\mathrm{FEV}_{1}$ or $\mathrm{DL}_{\mathrm{CO}}$ (Table 3 ).

The numbers of patients in A group, B group, C group, and D group were $47,25,46$, and 12 , respectively (Table 4). There were significant differences between these groups in BMI and FVC $(p<0.001$, and $p=0.018$, respectively), but not in $\mathrm{FEV}_{1}, \mathrm{DL}_{\mathrm{CO}}$, or CPI.

Table 1 Demographic, Clinical, and Physiologic Characteristics of Patients with Idiopathic Pulmonary Fibrosis

\begin{tabular}{lll}
\hline Characteristics & $\mathrm{N}$ & Value \\
\hline Age, years & 130 & $71(65-76)$ \\
Gender (Male/Female) & 130 & $104(80.0 \%) / 26(20.0 \%)$ \\
BMl, kg/m & 130 & $23.1(20.7-25.9)$ \\
Smoking history & 130 & $102(78.5 \%) / 28(21.5 \%)$ \\
(current or past/never) & & \\
Pack-years & 130 & $30(2-46)$ \\
FVC \%pred., \% & 130 & $76.2(63.9-89.1)$ \\
FEV $\%$ pred., \% & 130 & $76.3(65.8-90.2)$ \\
FEV ${ }_{1} /$ FVC, \% & 130 & $83.0(76.8-87.8)$ \\
DLCO \%pred., \% & 124 & $70.1(50.8-85.7)$ \\
CPI & 124 & $31.3(18.2-45.4)$ \\
KL-6, U/ml & 129 & $956(623-1506)$ \\
GAP stage (I/II/II) & 124 & $71(57.3 \%) / 50(40.3 \%) / 3(2.4 \%)$ \\
Follow-up period, years & 130 & $3.0(1.4-3.8)$ \\
\hline Data are presented as number
\end{tabular}

Data are presented as number or median (interquartile range) $B M I$ body mass index, FVC forced vital capacity, $F E V_{1}$ forced expiratory volume in $1 \mathrm{~s}$; $\mathrm{DL}_{\mathrm{CO}}$, diffusing capacity of the lungs for carbon monoxide, $C P I$ composite physiologic index, KL-6 Krebs von den Lungen-6, GAP gender, age, and physiology 
Table 2 Comparison of Clinical Features Between Convex Pattern and Non-convex Pattern of Flow-volume Curve

\begin{tabular}{llll}
\hline & Convex pattern $(n=93)$ & Non-convex pattern $(n=37)$ & $p$ value \\
\hline Age, years & $72(65-77)$ & $69(64-75)$ & 0.183 \\
Gender (male/female) & $70(75.3 \%) / 23(24.7 \%)$ & $34(91.9 \%) / 3(8.1)$ & $0.033^{*}$ \\
BMl, kg/m & $22.4(20.2-24.7)$ & $23.6(22.9-28.8)$ & $<0.001$ \\
Pack-years & $26(0-41)$ & $39(21-60)$ & 0.007 \\
FVC \%pred., \% & $76.1(62.6-89.2)$ & $78.8(65.7-89.4)$ & 0.488 \\
FEV $\%$ pred., \% & $79.2(68.3-92.8)$ & $71.3(64.5-84.3)$ & 0.059 \\
DLco \%pred., \% & $70.1(50.2-87.6)^{* *}$ & $68.4(54.4-77.9)$ & 0.552 \\
CPI & $31.8(19.1-47.6)^{* *}$ & $31.5(17.6-43.5)$ & 0.755 \\
KL-6, U/ml & $960(603-1717)^{* * *}$ & $953(628-1458)$ & 0.460 \\
GAP stage & $1(1-2)^{* *}$ & $1(1-2)$ & 0.377
\end{tabular}

Data are presented as number or median (interquartile range)

$p$ values derived by Mann-Whitney $U$ test. ${ }^{*} p$ values derived by chi-square test

${ }^{* *} n=87$ and ${ }^{* * *} n=92$

$B M I$ body mass index, FVC forced vital capacity, $F E V_{1}$ forced expiratory volume in $1 \mathrm{~s}, D L_{C O}$ diffusing capacity of the lungs for carbon monoxide, $C P I$ composite physiologic index, KL-6 Krebs von den Lungen-6, GAPs gender, age, and physiology

\section{CT image quantitation of honeycombing area and emphysematous area}

The median (interquartile range) \%HA and \%sLAA were $3.0 \%(1.3-5.1 \%)$ and $6.0 \%$ (3.5-9.2\%), respectively. There were no significant differences between the convex and non-convex patterns in terms of the \%HA and \%sLAA (Table 5). In contrast, significant differences were found between the concave and non-concave patterns only in the \%HA ( $p=0.009$, Table 6). Among the four groups, significant differences were observed only in the \%HA ( $p=0.046$, Table 7).

Among the CT findings, only the \%HA of the upper/ peripheral lung area was significantly different among the four groups $(p=0.005$, Table 7$)$; no intergroup differences were observed in the \%sLAA of any lung area.

\section{Prediction of mortality based on flow-volume curve patterns}

The Kaplan-Meier survival curve demonstrated a significant difference between the concave and non-concave patterns, but not between the convex and non-convex patterns (Fig. S1A, S1B). Among the four groups, patients in $\mathrm{C}$ group had the worst survival rates (Fig. S1C). The survival curve also showed a significant difference in mortality between $C$ group and non- $C$ group (logrank test; $p=0.010$, Fig. 4 ). In the Cox hazard regression analysis adjusted for age, gender, BMI, and smoking history in terms of pack-years, the $\mathrm{C}$ group was a significant predictor of mortality for IPF (hazard ratio, 2.19; 95\% confidence interval [CI]: $1.07-4.49 ; \quad p=0.032$, Table 8).

Table 3 Comparison of Clinical Features Between Concave Pattern and Non-concave Pattern of Flow-volume Curve

\begin{tabular}{|c|c|c|c|}
\hline & Concave pattern $(n=72)$ & Non-concave pattern $(n=58)$ & $p$ value \\
\hline Age, years & $69(63-75)$ & $73(66-77)$ & 0.034 \\
\hline Gender (male/female) & $58(80.6 \%) / 14(19.4 \%)$ & $46(79.3 \%) / 12(20.7 \%)$ & $0.860^{*}$ \\
\hline $\mathrm{BMl}, \mathrm{kg} / \mathrm{m}^{2}$ & $23.9(22.1-26.5)$ & $21.1(19.8-23.5)$ & $<0.001$ \\
\hline Pack-years & $30(4-46)$ & $25(1-47)$ & 0.558 \\
\hline FVC \%pred., \% & $79.7(68.4-92.9)$ & $68.1(59.1-86.2)$ & 0.011 \\
\hline FEV ${ }_{1} \%$ pred., $\%$ & $75.9(66.2-89.2)$ & $76.9(64.1-92.8)$ & 0.912 \\
\hline $\mathrm{DL}_{\mathrm{CO}} \%$ pred., \% & $70.8(53.8-84.0)^{* *}$ & $67.7(46.1-86.9)^{* * *}$ & 0.330 \\
\hline CPI & $28.7(18.7-40.9)^{* *}$ & $35.8(18.3-50.3)^{* * *}$ & 0.039 \\
\hline $\mathrm{KL}-6, \mathrm{U} / \mathrm{ml}$ & $956(648-1476)^{* * * *}$ & $979(565-1544)$ & 0.919 \\
\hline GAP stage & $1(1-2)^{* *}$ & $2(1-2) * * *$ & 0.033 \\
\hline
\end{tabular}

Data are presented as number or median (interquartile range) $p$ values derived by Mann-Whitney $U$ test. ${ }^{*} p$ values derived by chi-square test ${ }^{* *} n=70,{ }^{* * *} n=54$, and ${ }^{* * * *} n=71$

$B M I$ body mass index, $F V C$ forced vital capacity, $F E V$, forced expiratory volume in $1 \mathrm{~s}, D L_{C O}$ diffusing capacity of the lungs for carbon monoxide, $C P I$ composite physiologic index, KL-6 Krebs von den Lungen-6, GAP gender, age, and physiology 
Table 4 Comparison of Clinical Features Mixed Convex Pattern and Concave Pattern of Flow-volume Curve

\begin{tabular}{|c|c|c|c|c|c|}
\hline & $\begin{array}{l}\text { A group } \\
(n=47)\end{array}$ & $\begin{array}{l}\text { B group } \\
(n=25)\end{array}$ & $\begin{array}{l}\text { C group } \\
(n=46)\end{array}$ & $\begin{array}{l}\text { D group } \\
(n=12)\end{array}$ & $p$ value \\
\hline Age, years & $68(63-76)$ & $69(64-75)$ & $73(69-78)$ & $71(63-75)$ & 0.104 \\
\hline Gender (male/female) & $35 / 12$ & $23 / 2$ & $35 / 11$ & $11 / 1$ & $0.203^{*}$ \\
\hline $\mathrm{BMl}, \mathrm{kg} / \mathrm{m}^{2}$ & $23.6(21.4-26.0)$ & $25.4(23.1-29.3)$ & $20.8(19.5-23.5)$ & $23.0(20.7-25.3)$ & $<0.001$ \\
\hline Pack-years & $27(0-40)$ & $40(22-56)$ & $19(0-44)$ & $38(8-70)$ & 0.064 \\
\hline FVC \%pred., \% & $81.4(68.2-98.4)$ & $76.2(67.1-86.7)$ & 67.0 (57.9-84.4) & $81.2(65.1-98.8)$ & 0.018 \\
\hline FEV ${ }_{1} \%$ pred., $\%$ & $81.1(69.9-93.8)$ & $68.2(64.8-80.0)$ & $76.3(65.2-91.4)$ & $78.2(63.8-98.8)$ & 0.103 \\
\hline DL $L_{C O} \%$ pred., \% & $73.8(53.1-86.6) * *$ & $69.6(55.1-82.4)$ & $68.8(46.2-90.2)^{* * *}$ & $71.3(43.2-77.7)$ & 0.812 \\
\hline CPI & $27.3(19.7-40.7)^{* *}$ & $31.1(14.6-41.3)$ & $35.8(17.1-49.9)^{* * *}$ & $29.3(21.7-49.8)$ & 0.226 \\
\hline $\mathrm{KL}-6, \mathrm{U} / \mathrm{ml}$ & 935 (686-1568) & 960 (467-1519) & $1070(502-1776)$ & $918(652-1088)$ & 0.883 \\
\hline GAP stage & $1(1-2)^{* *}$ & $1(1-2)$ & $2(1--2)^{* * *}$ & $2(1-2)$ & 0.125 \\
\hline
\end{tabular}

Data are presented as number or median (interquartile range)

$p$ values derived by Kruskal-Wallis test. ${ }^{*} p$ values derived by chi-square test

${ }^{* *} n=45$, and ${ }^{* * *} n=42$

A group, the patients with the convex/concave pattern of flow volume curve; B group, the non-convex/concave pattern; C group, the convex/non-concave pattern; D group, the non-convex/non-concave pattern

$B M I$ body mass index, FVC forced vital capacity, $F E V_{1}$ forced expiratory volume in $1 \mathrm{~s}, D L_{c O}$ diffusing capacity of the lungs for carbon monoxide, $C P I$ composite physiologic index, KL-6 Krebs von den Lungen-6, GAP gender, age, and physiology

\section{Discussion}

In this study, we investigated the relationship between the FV curve patterns on the PFT with clinical and radiological features in patients with IPF. Our results demonstrated that the patients in $\mathrm{C}$ group, with a convex/non-concave pattern, had higher mortality rates than those in the other groups, and suggested that this pattern may be a prognostic factor in IPF.

We first divided the patterns of the FV curve into two categories based on visual inspection: convex and nonconvex. Initially, we assumed that the convex pattern was associated with more severe fibrosis than the nonconvex pattern. However, there were no significant differences between the two types in any of the PFT values or CPI. Furthermore, the degree of fibrosis and emphysema evaluated using quantitative $\mathrm{CT}$ analysis were also similar between the two patterns. Next, we categorized the FV curve pattern into two other categories based on the $\mathrm{MEF}_{50} / \mathrm{MEF}_{25}$ ratio. We expected that the concave pattern would have more emphysematous lesions than the non-concave pattern. However, there were no significant differences between the two patterns in the

Table 5 Comparison of Radiological Features Between Convex Pattern and Non-convex Pattern of Flow-volume Curve

\begin{tabular}{llll}
\hline & Convex pattern $(\mathrm{n}=93)$ & Non-convex pattern $(\mathrm{n}=37)$ & $p$ value \\
\hline Total lung area, L & $3.52(2.92-4.20)$ & $3.56(3.09-4.18)$ & 0.630 \\
$\mathrm{HA}, \mathrm{ml}$ & $115(56-173)$ & $93(46-132)$ & 0.247 \\
\%HA, \% & $3.2(1.4-5.9)$ & $2.7(1.2-4.2)$ & 0.263 \\
SLAA, ml & $207(103-372)$ & $227(135-424)$ & 0.191 \\
\%sLAA, \% & $5.9(3.2-8.8)$ & $6.0(4.3-9.9)$ & 0.150 \\
Upper/peripheral \%HA, \% & $2.1(0.8-4.3)$ & $1.4(0.7-2.6)$ & 0.095 \\
Upper/central \%HA, \% & $0.2(0.0-0.6)$ & $0.1(0.0-0.2)$ & 0.293 \\
Lower/peripheral \%HA, \% & $5.7(3.2-9.5)$ & $5.6(2.8-7.6)$ & 0.364 \\
Lower/central \%HA, \% & $1.2(0.2-3.5)$ & $0.9(0.3-3.0)$ & 0.716 \\
Upper/peripheral \%sLAA, \% & $6.7(3.9-9.7)$ & $7.5(5.4-12.0)$ & 0.103 \\
Upper/central \%LLAA, \% & $7.0(4.2-11.2)$ & $8.5(5.2-14.4)$ & 0.153 \\
Lower/peripheral \%sLAA, \% & $4.7(2.4-7.5)$ & $5.2(3.3-7.7)$ & 0.260 \\
Lower/central \%sLAA, \% & $5.1(2.8-8.2)$ & $6.0(3.7-9.5)$ & 0.158 \\
\hline Datare
\end{tabular}

Data are presented as median (interquartile range)

$p$ values derived by Mann-Whitney $U$ test

$\% \mathrm{HA}$, computed-tomography-derived \%honeycombing area; \%sLAA, computed-tomography-derived \%subtracted low attenuation area 
Table 6 Comparison of Radiological Features Between Concave Pattern and Non-concave Pattern of Flow-volume Curve

\begin{tabular}{llll}
\hline & Concave pattern $(\mathrm{n}=72)$ & Non-concave pattern $(\mathrm{n}=58)$ & $p$ value \\
\hline Total lung area, L & $3.60(3.16-4.28)$ & $3.47(2.81-4.04)$ & 0.161 \\
$\mathrm{HA}, \mathrm{ml}$ & $83(44-151)$ & $118(75-187)$ & $3.5(2.1-6.5)$ \\
\%HA, \% & $2.4(1.2-4.1)$ & $220(73-418)$ & 0.017 \\
SLAA, ml & $205(119-363)$ & $6.0(2.9-11.0)$ & 0.881 \\
\%sLAA, \% & $5.9(3.7-8.0)$ & $2.4(1.2-5.2)$ & 0.815 \\
Upper/peripheral \%HA, \% & $1.2(0.6-2.9)$ & $0.2(0.0-0.7)$ & 0.001 \\
Upper/central \%HA, \% & $0.1(0.0-0.3)$ & $6.6(4.2-10.2)$ & 0.048 \\
Lower/peripheral \%HA, \% & $4.6(2.8-7.6)$ & $1.7(0.5-4.0)$ & 0.029 \\
Lower/central \%HA, \% & $0.7(0.2-2.3)$ & $6.5(3.8-11.2)$ & 0.022 \\
Upper/peripheral \%sLAA, \% & $6.8(4.5-9.8)$ & $7.6(3.6-12.7)$ & 0.538 \\
Upper/central \%sLAA, \% & $7.2(4.7-11.2)$ & $5.1(2.5-8.7)$ & 0.687 \\
Lower/peripheral \%sLAA, \% & $4.6(2.9-7.1)$ & $6.0(2.6-10.1)$ & 0.558 \\
Lower/central \%sLAA, \% & $4.9(3.4-7.6)$ & 0.579 \\
\hline
\end{tabular}

Data are presented as median (interquartile range)

$p$ values derived by Mann-Whitney $U$ test

$\% \mathrm{HA}$, computed-tomography-derived \%honeycombing area; \%sLAA, computed-tomography-derived \%subtracted low attenuation area

degree of emphysema. Based on these results, we hypothesized that not only the degree, but also the distribution of radiological findings would affect the patterns of the FV curve. The additional quantitative CT analysis revealed a significant difference among the four groups in the \%HA of the upper/peripheral lung area.

The concave pattern, i.e., $\mathrm{MEF}_{50} / \mathrm{MEF}_{25}$-ratio $\geq 4$, is reportedly affected by peripheral airway obstruction [22, 23]. However, the concave pattern in our study was not associated with $\% \mathrm{FEV}_{1}$ or \%sLAA. The obstruction of the peripheral airways due to emphysematous change may be prevented by traction bronchiectasis around the peripheral airway; thus, the concave pattern may be lost. In the additional analysis of the \%HA/\%sLAA ratio, the ratio of the upper/peripheral lung area significantly affected the concave pattern of the FV curve (Table S1). The concave pattern of the FV curve in IPF may depend on both the degree and the distribution of fibrosis.

The convex pattern has been reported in patients with ILD [12] and is more common among young people [14,

Table 7 Comparison of Radiological Features Among Four groups of Flow-volume Curve

\begin{tabular}{|c|c|c|c|c|c|}
\hline & $\begin{array}{l}\text { A group } \\
(n=47)\end{array}$ & $\begin{array}{l}\text { B group } \\
(n=25)\end{array}$ & $\begin{array}{l}\text { C group } \\
(n=46)\end{array}$ & $\begin{array}{l}D \text { group } \\
(n=12)\end{array}$ & $p$ value \\
\hline Total lung area, $\mathrm{L}$ & $3.64(3.19-4.40)$ & $3.56(2.98-3.96)$ & $3.43(2.72-3.99)$ & $3.67(3.21-4.86)$ & 0.270 \\
\hline $\mathrm{HA}, \mathrm{ml}$ & $81(44-157)$ & $84(43-141)$ & $124(75-193)$ & $101(72-130)$ & 0.085 \\
\hline$\% \mathrm{HA}, \%$ & $2.4(1.2-4.0)$ & $2.3(1.2-4.5)$ & $4.2(2.1-6.8)$ & $3.1(2.2-4.1)$ & 0.046 \\
\hline sLAA, ml & $207(110-375)$ & $180(135-337)$ & $203(69-372)$ & $389(115-553)$ & 0.264 \\
\hline$\% s L A A, \%$ & $6.1(3.4-8.0)$ & $5.7(4.3-8.0)$ & $5.6(2.7-9.4)$ & $9.1(3.5-15.7)$ & 0.291 \\
\hline Upper/peripheral \%HA, \% & $1.2(0.6-2.9)$ & $1.4(0.5-2.7)$ & $3.1(1.3-5.5)$ & $1.5(1.1-2.5)$ & 0.005 \\
\hline Upper/central \%HA, \% & $0.1(0.0-0.4)$ & $0.1(0.0-0.2)$ & $0.2(0.1-1.0)$ & $0.1(0.0-0.2)$ & 0.069 \\
\hline Lower/peripheral \%HA, \% & $4.7(2.9-7.4)$ & $4.5(2.6-7.7)$ & $7.1(3.9-11.5)$ & $5.8(4.6-6.8)$ & 0.131 \\
\hline Lower/central \%HA, \% & $0.7(0.2-2.1)$ & $0.9(0.2-2.6)$ & $1.7(0.6-4.1)$ & $0.8(0.3-3.3)$ & 0.113 \\
\hline Upper/peripheral \%sLAA, \% & $6.8(4.2-9.7)$ & $6.7(5.9-10.9)$ & $6.0(3.7-6.0)$ & $10.1(4.0-14.1)$ & 0.297 \\
\hline Upper/central \%sLAA, \% & $7.1(4.7-11.1)$ & $7.7(6.0-13.4)$ & $6.5(3.6-11.9)$ & $10.2(3.3-17.5)$ & 0.529 \\
\hline Lower/peripheral \%sLAA, \% & $4.9(2.5-7.7)$ & $4.4(3.2-6.8)$ & $4.6(2.3-7.6)$ & $7.7(4.2-12.8)$ & 0.151 \\
\hline Lower/central \%sLAA, \% & $5.0(3.0-7.6)$ & $4.7(3.7-7.9)$ & $5.8(2.5-8.8)$ & $8.5(3.4-16.6)$ & 0.304 \\
\hline
\end{tabular}

Data are presented as number or median (interquartile range) $p$ values derived by Kruskal-Wallis test

A group, the patients with the convex/concave pattern of flow volume curve; B group, the non-convex/concave pattern; $C$ group, the convex/non-concave pattern; $D$ group, the non-convex/non-concave pattern

$\% \mathrm{HA}$, computed-tomography-derived \%honeycombing area; \%sLAA, computed-tomography-derived \%subtracted low attenuation area 


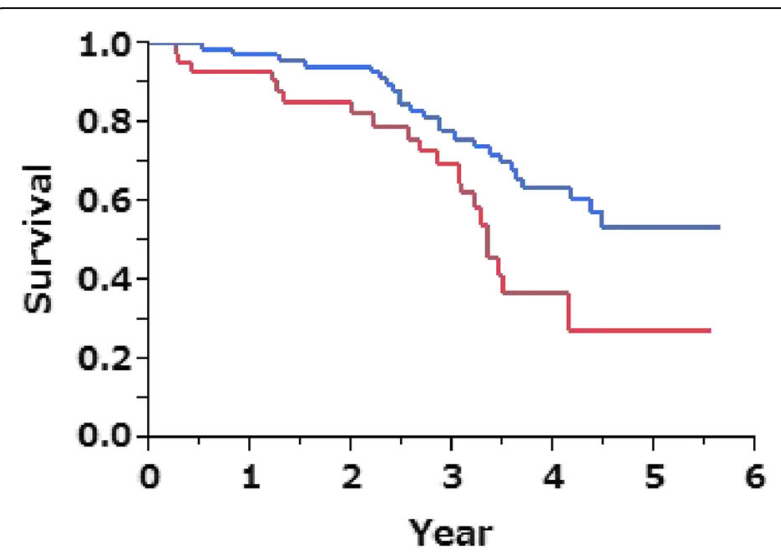

Fig. 4 Kaplan-Meier plot of survival probability. The patients in the $C$ group (red line) had worse survival than those in the other groups (blue line; log-rank test; $p=0.010$ )

15]. A previous study reported increased elastic recoil forces, decreased airway resistance, and decreased dynamic airway compression in the large bronchi in patients with ILD [12]. Patients with ILD may be able to exhale strongly because of expanded peripheral airways and fibrotic lung tissue. However, there were no significant associations between the convex pattern and \%FVC, $\mathrm{CPI}$, or \%HA in our study. The convex pattern is attributed to a 'choke point' in the lower trachea, indicating the flow-limiting area of the bronchial tree, and disappears with increasing age as the choke point moves

Table 8 Results of Cox's Hazard Regression Analysis for Predictors of Mortality Adjusted by Age, Gender, BMI, and Packyear

\begin{tabular}{llll}
\hline & $\mathrm{HR}$ & $95 \% \mathrm{Cl}$ & p value \\
\hline C group (vs non-C group) & 2.19 & $1.07-4.49$ & 0.032 \\
FVC \%pred., \% & 0.97 & $0.94-0.99$ & 0.002 \\
FEV \% pred., \% & 0.99 & $0.97-1.01$ & 0.289 \\
DLCo \%pred., \% & 0.97 & $0.95-0.99$ & 0.002 \\
CPI & 1.05 & $1.02-1.08$ & $<0.001$ \\
GAP stage & 1.93 & $0.98-3.74$ & 0.057 \\
KL-6, U/ml & 1.00 & $1.00-1.00$ & 0.360 \\
\%HA, \% & 1.26 & $1.13-1.40$ & $<0.001$ \\
\%sLAA, \% & 0.98 & $0.90-1.06$ & 0.665 \\
Convex pattern & 1.67 & $0.84-3.50$ & 0.143 \\
(vs Non-convex pattern) & & & \\
Concave pattern & 0.56 & $0.29-1.10$ & 0.091 \\
(vs Non-concave pattern) & & & \\
\hline
\end{tabular}

$H R$ hazard ratio, $\mathrm{Cl}$ confidence interval, \%HA computed-tomography-derived \%honeycombing area, \%sLAA computed-tomography-derived \%subtracted low attenuation area, BMI body mass index, FVC forced vital capacity, FEV , forced $^{2}$ expiratory volume in $1 \mathrm{~s}, D L_{C O}$ diffusing capacity of the lungs for carbon monoxide, CPI composite physiologic index, KL-6 Krebs von den Lungen-6, GAP gender, age, and physiology further down the bronchi due to loss of lung elastic recoil [24]. To compare the degree of flow limitation between the convex and non-convex patterns, the speed of expiration was evaluated (Table S2). The peak flow in the convex pattern was significantly slower than that in the non-convex pattern, while the $\mathrm{FEV}_{1}$ was similar between the two patterns. These results suggest that the heterogeneity of the exhalation flow may make up the choke point, indicating that the convex pattern may be easily affected by the degree of traction bronchiectasis. However, in this quantitative CT analysis, the HA includes both honeycombing lesions and traction bronchiectasis lesions, and it is difficult to clearly distinguish between these two lesion types [19]. This limitation of quantitative $\mathrm{CT}$ analysis may be the reason why there was no difference in the \%HA between the convex and non-convex patterns.

Among the four groups in our study, $\mathrm{C}$ group had a significantly higher value of the \%HA of the upper/peripheral lung area than the other groups. The FV curve may be easily affected by upper lung fibrosis because the upper lung is close to the trachea and the main bronchi. Fibrosis of the upper/peripheral lung area may reduce the peripheral airway obstruction and result in heterogeneous movement of the thorax, thereby causing heterogeneous flow of the exhalation and the choke point. These changes may be explained by comparing peak expiration flow in the FV curve between the four groups (Fig. S2).

The patients in $\mathrm{C}$ group had the worst prognoses in our study. This may be because they required more breathing effort due to heterogeneous movement of the thorax, and the heterogeneous movement may have caused a decrease in BMI. We cannot conclude whether the change in the FV curve is the cause or the result of the decrease in BMI. However, even in the analysis adjusted for BMI, the convex/non-concave pattern, as seen in $\mathrm{C}$ group, was a significant predictor of mortality in our study. Hence, we believe that this FV curve pattern is associated with a poorer prognosis and reduced BMI. Observation of the movement of the lung using 4D CT analysis has been recently attracting attention [25]. Future studies using a detailed analysis of lung movement are warranted to prove and establish our hypothesis regarding the heterogeneous movement of the thorax in this category of patients.

There were several limitations in the present study. First, this was a retrospective study with a small sample size, conducted at a single institution. Second, classification of the FV curve patterns into convex or non-convex patterns may not be completely objective. However, the concordance rate between the two reviewers was excellent. A prospective, multicenter study is needed to confirm the usefulness of FV curves in the prediction of prognosis in patients with IPF. 


\section{Conclusions}

The convex/non-concave pattern of the FV curve in IPF may be associated with the degree of fibrosis in the upper/peripheral lung area. The convex/non-concave pattern of the FV curve and the degree of fibrosis in the upper/peripheral lung area may be a predictor of mortality in patients with IPF. Therefore, we should pay attention not only to FVC and $\mathrm{DL}_{\mathrm{CO}}$, but also to the pattern of the FV curve and the distribution of fibrosis when evaluating the PFT and HRCT in IPF.

\section{Supplementary information}

Supplementary information accompanies this paper at https://doi.org/10. 1186/s12890-020-01254-z.

Additional file 1: Table S1. Comparison of \%HA/\%sLAA-ratio Between Concave Pattern and Non-concave Pattern of Flow-volume Curve. Table

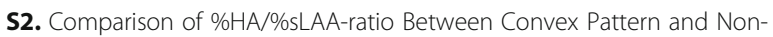
convex Pattern of Flow-volume Curve. Figure S1. Kaplan-Meier plots of survival probability. (A) The patients with a concave pattern (red line) had better survival than those with a non-concave pattern (blue line; log-rank test; $p=0.026)$. (B) There was no significant difference between the convex pattern (red line) and non-convex pattern (blue line; log-rank test; $p=0.234$ ). (C) Mixed convex and concave patterns, i.e., the $C$ group (blue line), had worse survival than the other groups (A group: red line, B group: green line, and D group: black line; log-rank test; $p=0.080)$. Figure S2. Median flow values at different expiratory flow levels in each group. The flow values in the A group (blue line) and $\mathrm{C}$ group (green line) had convex patterns. The forced expiration at the PEF level in the $C$ group was low compared with that in the other groups. PEF $=$ peak expiratory flow, MEF = maximal expiratory flow

\section{Abbreviations}

\%HA: Computed-tomography-derived \%honeycombing area;

\%sLAA: computed-tomography-derived \%subtracted low attenuation area; BMl: Body mass index; Cl: Confidence interval; COPD: Chronic obstructive pulmonary disease; CPFE: Combined pulmonary fibrosis and emphysema; CPI: Composite physiologic index; CT: computed tomography;

$\mathrm{DL}_{\mathrm{CO}}$ : Diffusing capacity for carbon monoxide; FEV ${ }_{1}$ : Forced expiratory volume in $1 \mathrm{~s}$; FV: Flow-volume; FVC: Forced vital capacity; GAP: Gender, age, and physiology; HA: Computed-tomography-derived honeycombing area; HRCT: High-resolution computed tomography; ILD: Interstitial lung disease; IPF: Idiopathic pulmonary fibrosis; KL-6: Krebs von den Lungen-6; LAA: Low attenuation area; MEF: Maximal expiratory flows; PFT: Pulmonary function test; PPFE: Pleuroparenchymal fibroelastosis; sLAA: Subtracted low attenuation area

\section{Acknowledgements}

Not applicable.

\section{Authors' contributions}

H. N. served as principal author, had full access to all the data in the study, and takes responsibility for the integrity of the data and the accuracy of the data analysis. T. O. contributed substantially to the conception and design of the study. R. O., K. I., and T. K. contributed to evaluate the flow-volume curves and to classify the pattern. T. B., S. K., and E. H. contributed to data collection. Y. N., I. K., and T. O. participated in drafting the article and critically revising it for important intellectual content. All the authors have read and approved the final manuscript.

\section{Funding}

Not applicable.

\section{Availability of data and materials}

The datasets used and/or analyzed during the current study are available from the corresponding author on reasonable request.

\section{Ethics approval and consent to participate}

The study protocol conformed to the Declaration of Helsinki and was approved by the ethic committee of Kanagawa Cardiovascular and Respiratory Center, with a waiver of the need for informed consent because of the retrospective study design.

\section{Consent for publication}

Not applicable.

\section{Competing interests}

The authors declare that they have no competing interests.

\section{Author details}

${ }^{1}$ Division of Respiratory Medicine, Department of Internal Medicine, Shiga University of Medical Science, Seta Tsukinowa-cho, Otsu, Shiga 520-2192, Japan. ${ }^{2}$ Department of Respiratory Medicine, Kanagawa Cardiovascular and Respiratory Center, Kanagawa, Japan. ${ }^{3}$ Department of Medical Oncology, Kindai University Faculty of Medicine, Osaka, Japan. ${ }^{4}$ Department of Pulmonary Medicine, Tokai University School of Medicine, Tokai University Tokyo Hospital, Tokyo, Japan.

Received: 25 December 2019 Accepted: 5 August 2020

Published online: 12 August 2020

\section{References}

1. Lynch DA, Godwin JD, Safrin S, Starko KM, Hormel P, Brown KK, Raghu G, King TE Jr, Bradford WZ, Schwartz DA, et al. High-resolution computed tomography in idiopathic pulmonary fibrosis: diagnosis and prognosis. Am J Respir Crit Care Med. 2005;172(4):488-93.

2. Nishimura K, Kitaichi M, Izumi T, Nagai S, Kanaoka M, Itoh H. Usual interstitial pneumonia: histologic correlation with high-resolution CT. Radiology. 1992; 182(2):337-42.

3. American Thoracic Society. Idiopathic pulmonary fibrosis: diagnosis and treatment. International consensus statement. American Thoracic Society (ATS), and the European Respiratory Society (ERS). Am J Respir Crit Care Med. 2000;161(2 Pt 1):646-64.

4. Collard HR, King TE Jr, Bartelson BB, Vourlekis JS, Schwarz MI, Brown KK Changes in clinical and physiologic variables predict survival in idiopathic pulmonary fibrosis. Am J Respir Crit Care Med. 2003;168(5):538-42.

5. Jegal Y, Kim DS, Shim TS, Lim CM, Do Lee S, Koh Y, Kim WS, Kim WD, Lee JS, Travis WD, et al. Physiology is a stronger predictor of survival than pathology in fibrotic interstitial pneumonia. Am J Respir Crit Care Med. 2005;171(6):639-44.

6. King TE Jr, Safrin S, Starko KM, Brown KK, Noble PW, Raghu G, Schwartz DA. Analyses of efficacy end points in a controlled trial of interferon-gamma1b for idiopathic pulmonary fibrosis. Chest. 2005;127(1):171-7.

7. Latsi PI, du Bois RM, Nicholson AG, Colby TV, Bisirtzoglou D, Nikolakopoulou A, Veeraraghavan S, Hansell DM, Wells AU. Fibrotic idiopathic interstitial pneumonia: the prognostic value of longitudinal functional trends. Am J Respir Crit Care Med. 2003;168(5):531-7.

8. Flaherty KR, Mumford JA, Murray S, Kazerooni EA, Gross BH, Colby TV, Travis WD, Flint A, Toews GB, Lynch JP 3rd, et al. Prognostic implications of physiologic and radiographic changes in idiopathic interstitial pneumonia. Am J Respir Crit Care Med. 2003;168(5):543-8.

9. Cottin V, Hansell DM, Sverzellati N, Weycker D, Antoniou KM, Atwood M, Oster G, Kirchgaessler KU, Collard HR, Wells AU. Effect of emphysema extent on serial lung function in patients with idiopathic pulmonary fibrosis. Am J Respir Crit Care Med. 2017;196(9):1162-71.

10. Sharafkhaneh A, Officer TM, Goodnight-White S, Rodarte JR, Boriek AM. Novel method for measuring effects of gas compression on expiratory flow. Am J Physiol Regul Integr Comp Physiol. 2004;287(2):R479-84.

11. Ingram RH Jr, Schilder DP. Effect of thoracic gas compression on the flowvolume curve of the forced vital capacity. Am Rev Respir Dis. 1966;94(1):56-63.

12. Piirila PL, Hodgson U, Wuorimaa T, Smith HJ, Sovijarvi AR. Thoracic gas compression during forced expiration in patients with emphysema, interstitial lung disease and obesity. BMC Pulmon Medi. 2014;14:34

13. Raghu G, Collard HR, Egan JJ, Martinez FJ, Behr J, Brown KK, Colby TV, Cordier JF, Flaherty KR, Lasky JA, et al. An official ATS/ERS/JRS/ALAT statement: idiopathic pulmonary fibrosis: evidence-based guidelines for diagnosis and management. Am J Respir Crit Care Med. 2011;183(6): $788-824$. 
14. Le Souef PN, Hughes DM, Landau LI. Shape of forced expiratory flowvolume curves in infants. Am Rev Respir Dis. 1988;138(3):590-7.

15. Shin HH, Sears MR, Hancox RJ. Prevalence and correlates of a 'knee' pattern on the maximal expiratory flow-volume loop in young adults. Respirology. 2014;19(7):1052-8.

16. Ley B, Ryerson CJ, Vittinghoff E, Ryu JH, Tomassetti S, Lee JS, Poletti V, Buccioli $\mathrm{M}$, Elicker BM, Jones KD, et al. A multidimensional index and staging system for idiopathic pulmonary fibrosis. Ann Intern Med. 2012; 156(10):684-91.

17. Wells AU, Desai SR, Rubens MB, Goh NS, Cramer D, Nicholson AG, Colby TV, du Bois RM, Hansell DM. Idiopathic pulmonary fibrosis: a composite physiologic index derived from disease extent observed by computed tomography. Am J Respir Crit Care Med. 2003;167(7):962-9.

18. Nishimura M. Guideline of respiratory function tests--spirometry, flow-volume curve, diffusion capacity of the lung. Nihon Kokyuki Gakkai Zasshi. 2004;Suppl: $1-56$.

19. Nakagawa H, Nagatani Y, Takahashi M, Ogawa E, Tho NV, Ryujin Y, Nagao T, Nakano Y. Quantitative CT analysis of honeycombing area in idiopathic pulmonary fibrosis: correlations with pulmonary function tests. Eur J Radiol. 2016;85(1):125-30

20. Sakai N, Mishima M, Nishimura K, Itoh H, Kuno K. An automated method to assess the distribution of low attenuation areas on chest $\mathrm{CT}$ scans in chronic pulmonary emphysema patients. Chest. 1994;106(5):1319-25.

21. Nakano Y, Muro S, Sakai H, Hirai T, Chin K, Tsukino M, Nishimura K, Itoh H, Pare PD, Hogg JC, et al. Computed tomographic measurements of airway dimensions and emphysema in smokers. Correlation with lung function. Am J Respir Crit Care Med. 2000;162(3 Pt 1):1102-8.

22. Sun XW, Gu SY, Li QY, Ren L, Shen JM, Wan HY, Huang SG, Deng WW. Pulmonary function parameters in high-resolution computed tomography phenotypes of chronic obstructive pulmonary disease. Am J Med Sci. 2015; 349(3):228-33

23. Nemoto T, Shibata $Y$, Osaka D, Abe $S$, Inoue $S$, Tokairin $Y$, Igarashi A, Yamauchi K, Kimura T, Kishi H, et al. Impact of cigarette smoking on maximal expiratory flows in a general population: the Takahata study. Intern Med. 2011:50(21):2547-55.

24. Mead J, Turner JM, Macklem PT, Little JB. Significance of the relationship between lung recoil and maximum expiratory flow. J Appl Physiol. 1967; 22(1):95-108.

25. Yamashiro T, Moriya H, Matsuoka S, Nagatani Y, Tsubakimoto M, Tsuchiya N, Murayama S. Asynchrony in respiratory movements between the pulmonary lobes in patients with COPD: continuous measurement of lung density by 4-dimensional dynamic-ventilation CT. Int J Chronic Obstruct Pulmon Dis. 2017;12:2101-9.

\section{Publisher's Note}

Springer Nature remains neutral with regard to jurisdictional claims in published maps and institutional affiliations.

Ready to submit your research? Choose BMC and benefit from:

- fast, convenient online submission

- thorough peer review by experienced researchers in your field

- rapid publication on acceptance

- support for research data, including large and complex data types

- gold Open Access which fosters wider collaboration and increased citations

- maximum visibility for your research: over $100 \mathrm{M}$ website views per year

At $\mathrm{BMC}$, research is always in progress.

Learn more biomedcentral.com/submissions 